\title{
Editorial: The Relationship Between Cancer Predisposition and Primary Immunodeficiency
}

\author{
Fabian Hauck ${ }^{1}$, Andrew R. Gennery ${ }^{2}$ and Markus G. Seidel ${ }^{3 *}$ \\ ${ }^{1}$ Pediatric Immunology and Rheumatology, Department of Pediatrics, Dr. von Hauner Children's Hospital, University Hospital, \\ Ludwig-Maximilians-University Munich, Munich, Germany, ${ }^{2}$ Department of Paediatric Immunology + HSCT, Great North \\ Children's Hospital, Institute of Cellular Medicine, Newcastle University, Newcastle upon Tyne, United Kingdom, ${ }^{3}$ Research \\ Unit for Pediatric Hematology and Immunology, Division of Pediatric Hemato-Oncology, Department of Pediatric and \\ Adolescent Medicine, Medical University Graz, Graz, Austria
}

Keywords: inborn error of immunity, IEI, primary immunodeficiency, PID, cancer predisposition syndrome, CPS

\section{Editorial on the Research Topic}

The Relationship Between Cancer Predisposition and Primary Immunodeficiency

\section{INTRODUCTION}

The risk of malignancies is higher in patients with genetically determined inborn errors of immunity (IEI) than in the general population $(1,2)$. However, the degree of tumor predisposition and the underlying cellular and molecular mechanisms vary through the categories of IEI $(3,4)$. In addition to perturbed tumor immune surveillance in IEI and chronic inflammation or infections, the molecular defect per se that causes IEI may predispose to tumorigenesis (5). This suggests that malignancy in IEI may not merely be a consequence of immune deficiency, but occur in parallel to or even precede immune deficiency. Furthermore, in genetically determined DNA repair deficiencies the particular IEI may be perceived as an add-on to tumor predisposition (6-8). Additionally, deregulation of epigenetic factors related to IEI or its treatment such as alterations of the microbiome can contribute to tumor predisposition $(9,10)$.

The Research Topic covers many aspects of this increasingly appreciated clinical and basic scientific field. Furthermore, based on presentations and discussions directly or indirectly related to the process of the present collection, additional initiatives were launched and are ongoing. The 2019 focused meeting of the European Society of Immunodeficiencies in Brussels_-"Malignancy and PID" (https://esidmeeting.org)—exemplifies this bringing together of specialists.

\section{COMPOSITION}

\section{Large Cohort Studies}

Two nationwide studies of common variable immunodeficiency (CVID) and one large international study of patients with haploinsufficiency of CTLA4 were conducted and provide insight into the cancer risk in these relatively frequent and highly relevant entities (Egg et al.; Kralickova et al.; Pulvirenti et al.). The need for awareness and appropriate screening measures is highlighted.

\section{Systematic Review}

A comprehensive meta-review on lymphoid malignancies IEI structured according to the classification of the international union of immunological societies (IUIS), gives a clear, detailed, 
and helpful overview of the current knowledge, types, and distribution of $\mathrm{B}$ and $\mathrm{T}$ cell lymphoid malignancies associated with IEI (Riaz et al.).

\section{Perspective}

The "Current understanding and research priorities..." in the challenging field of malignancies in IEI were defined, discussed, prioritized, and summarized by an interdisciplinary working group consisting of hematologists, oncologists, immunologists, tumor biologists, and geneticists and are presented (Bomken et al.).

\section{Small Cohort Studies, Single Entity or Patient Reports, or Reviews}

A diverse collection of relevant clinical observations was reported, ranging from a single center long-term experience of malignancies in IEI (Maffeis et al. in press), over lymphomagenesis in STK4 deficiency or ataxia telangiectasia, variable phenotypes of Cernunnos/XLF deficiency, as well as the study of clinical and biological signs of immune deficiency in patients with the cancer predisposition syndrome constitutional mismatch repair deficiency (Recio et al.; Schipp et al.; Tatfi et al.; Tesch et al.). Additionally, the risk of malignancies in patients with secondary immunodeficiency due to immunosuppressive drugs in the framework of solid organ transplantation is reported, aiming at identifying specific drug-dependent mechanisms and risk factors (Cangemi et al.).

\section{Conceptual Review and Mini Reviews}

One large conceptual review embedded the "Closely related concepts" of IEI and cancer predisposition syndromes into an integrative framework (Haas), while smaller (mini) reviews focused on tumor profiles in IEI, in Down Syndrome, or on common genetic bases of cancer and IEI (Derpoorter et al.; Satge; Satge and Seidel).

\section{Basic and Methodological Research}

A mouse study on the effects of the loss of JAK1 on innate immunity, with a potential consequence of reduced

\section{REFERENCES}

1. Mueller BU, Pizzo PA. Cancer in children with primary or secondary immunodeficiencies. J Pediatric. (1995) 126:1-10. doi: 10.1016/S0022-3476(95)70491-4

2. Jonkman-Berk BM, van den Berg JM, Ten Berge IJ, Bredius RG, Driessen GJ, Dalm VA, et al. Primary immunodeficiencies in the Netherlands: national patient data demonstrate the increased risk of malignancy. Clin Immunol. (2015) 156:154-62. doi: 10.1016/j.clim.2014.10.003

3. Salavoura K, Kolialexi A, Tsangaris G, Mavrou A. Development of cancer in patients with primary immunodeficiencies. Anticancer Res. (2008) 28:1263-9.

4. Mayor PC, Eng KH, Singel KL, Abrams SI, Odunsi K, Moysich KB, et al. Cancer in primary immunodeficiency diseases: cancer incidence in the United States Immune Deficiency Network Registry. J Allergy Clin Immunol. (2018) 141:1028-35. doi: 10.1016/j.jaci.2017.05.024 tumor surveillance (Witalisz-Siepracka et al.), and a methodological study on improved early detection of the transformation risk in severe congenital neutropenia (Klimiankou et al.) complete the spectrum of articles.

\section{CONCLUSIONS AND PERSPECTIVES}

While it is evident that the concept of cancer predisposition and immune deficiency as opposite sites of the same genetic coin is still in its infancy, we at this point in time can state that it is born and rapidly growing.

We envision that in the era of systems biology and "omics" technologies there will be major advances not only in basic science, but as well in the ways geneticists, tumor biologists, immunologists, and oncologists will work together to finally improve diagnosis, treatment and patient outcome both in the sense of overall survival and in terms of quality adjusted life years and reproductivity.

\section{AUTHOR CONTRIBUTIONS}

FH and MS drafted the article. AG approved it.

\section{FUNDING}

FH was funded by the Care-for-Rare Foundation (C4R, project number 160073), the German Center for Infection Research (DZIF, project number TTU 07.909), the Else KrönerFresenius Stiftung (EKFS, project number 2017_A110), and the German Federal Ministry of Education and Research (BMBF, project number 01GM1910C). MS was in part sponsored by the Styrian Children's Cancer Aid (Steirische Kinderkrebshilfe).

\section{ACKNOWLEDGMENTS}

We acknowledge the contribution of all authors, reviewers, and editors that have contributed to the realization of the Research Topic.
5. Hauck F, Voss R, Urban C, Seidel MG. Intrinsic and extrinsic causes of malignancies in patients with primary immunodeficiency disorders. J Allergy Clin Immunol. (2018) 141:59-68 e54. doi: 10.1016/j.jaci.2017. 06.009

6. Suarez F, Mahlaoui N, Canioni D, Andriamanga C, Dubois d'Enghien C, Brousse $\mathrm{N}$, et al. Incidence, presentation, and prognosis of malignancies in ataxia-telangiectasia: a report from the French national registry of primary immune deficiencies. J Clin Oncol. (2015) 33:202-8. doi: 10.1200/JCO.2014.56.5101

7. Wolska-Kusnierz B, Gregorek H, Chrzanowska K, Piatosa B, Pietrucha B, Heropolitanska-Pliszka E, et al. Nijmegen breakage syndrome: clinical and immunological features, long-term outcome and treatment options - a retrospective analysis. J Clin Immunol. (2015) 35:538-49. doi: 10.1007/s10875-015-0186-9

8. Kindler O, Quehenberger F, Benesch M, Seidel MG. The Iceberg Map of germline mutations in childhood cancer: focus on primary 
immunodeficiencies. Curr Opin Pediatric. (2018) 30:855-63. doi: 10.1097/MOP.0000000000000680

9. Hamada T, Nowak JA, Milner DA Jr, Song M, Ogino S. Integration of microbiology, molecular pathology, and epidemiology: a new paradigm to explore the pathogenesis of microbiomedriven neoplasms. J Pathol. (2019) 247:615-28. doi: 10.1002/path. 5236

10. Talotta R, Sarzi-Puttini P, Atzeni F. Microbial agents as putative inducers of B cell lymphoma in sjogren's syndrome through an impaired epigenetic control: the state-of-the-art. J Immunol Res. (2019) 2019:8567364. doi: $10.1155 / 2019 / 8567364$
Conflict of Interest Statement: The authors declare that the research was conducted in the absence of any commercial or financial relationships that could be construed as a potential conflict of interest.

Copyright (c) 2019 Hauck, Gennery and Seidel. This is an open-access article distributed under the terms of the Creative Commons Attribution License (CC BY). The use, distribution or reproduction in other forums is permitted, provided the original author(s) and the copyright owner(s) are credited and that the original publication in this journal is cited, in accordance with accepted academic practice. No use, distribution or reproduction is permitted which does not comply with these terms. 